\title{
ASPEK HUMANISME PADA DONGENG
}

\author{
Oleh: \\ Ahmad Muzaki, Ni Wayan Ayu Permata Sari \\ Program Studi Pendidikan Bahasa dan Sastra Indoesia \\ Fakultas Bahasa dan Seni Universitas Indraprasta PGRI \\ Jl. Nangka 58C Tanjung Barat, Jakarta Selatan, 12530 \\ ahmadmuzaki8@gmail.com,niwynayups@gmail.com
}

\begin{abstract}
This research is deskrpitif qualitative research that seeks to describe and formulate the data on the fairy tale aspect of humanism. The technique used to collect data in this research is the study of documentation, which is an attempt to trace the sources of information on the content aspect of humanism contained in fairy tales choice. A study of 10 fairy tales Indonesia produced a number of data and findings on aspects of humanism. Of the 10 studied fairy tales found as many as 68 aspects of humanism. Aspects of humanism found in fairy tales will be described sequentially from the turnout at most that the basic physiological needs as much as 29 or $42.65 \%$; the need for security as much as 14 or $20.59 \%$; needs to be appreciated as much as 10 or $14.71 \%$; self-actualization needs as much as 9 or $13.24 \%$; the need to be loved or cherished as much as 6 or $8.82 \%$.
\end{abstract}

Keywords : Aspects of humanism, tales

\begin{abstract}
ABSTRAK
Penelitian ini adalah penelitian deskrpitif kualitatif yaitu penelitian yang berupaya menggambarkan dan merumuskan data aspek humanisme pada dongeng. Teknik yang digunakan untuk mengumpulkan data dalam penelitian ini adalah studi dokumentasi, yaitu suatu upaya melacak sumber-sumber informasi kandungan aspek humanisme yang terdapat dalam dongeng pilihan. Penelitian yang dilakukan terhadap 10 dongeng anak Indonesia menghasilkan sejumlah data dan temuan tentang aspek-aspek humanisme. Dari 10 dongeng yang diteliti ditemukan sebanyak 68 aspek humanisme.Aspek humanisme yang ditemukan dalam dongeng akan diuraikan secara berurutan dari yang pemunculannya paling banyak yaitu kebutuhan fisiologi dasar sebanyak 29 atau 42,65\%; kebutuhan akan rasa aman sebanyak 14 atau 20,59\%; kebutuhan untuk dihargai sebanyak 10 atau 14,71\%; kebutuhan aktualisasi diri sebanyak 9 atau 13,24\%; kebutuhan untuk dicintai atau disayangi sebanyak 6 atau 8,82\%.
\end{abstract}

Kata kunci: Aspek humanisme, dongeng 


\section{PENDAHULUAN}

Dongeng merupakan salah satu di antara bentuk sastra yang peka terhadap cerminan masyarakat. Manusia menyadari bahwa dirinya adalah agen perubahan dalam sejarah peradaban. Sebagai subjek yang mempunyai kesadaran diri, manusia dapat berhubungan dengan objek yang ada di luar dirinya. Melalui kemampuan akal budi dan daya nalarnya, manusia dapat memahami realitas di luar dirinya dan tidak hanya memahami realitas, tetapi juga dapat mengubahnya demi kepentingan manusia itu sendiri. Sebagai makhluk yang berkehendak, manusia mempunyai kebebasan untuk menentukan hidupnya sendiri. Dengan kata lain, manusia adalah makhluk otonom yang hidupnya tidak dikendalikan oleh faktor di luar dirinya, tetapi diarahkan dan diatur oleh kekuatan internal yang dimilikinya. Nilai-nilai yang dikembangkan oleh gerakan humanisme seperti kebebasan, aktualisasi diri, dan otonomi di satu sisi telah membawa manusia pada kesadaran baru atas kesamaan harkat dan martabat, menentang berbagai ketidakadilan, diskriminasi, dan perbudakan.

Aspek-aspek humanisme di atas dapat ditemui dalam berbagai karya sastra, seperti dongeng. Sebagai cerita khayal yang berkembang di masyarakat yang bertujuan untuk mendidik serta menghibur, tentunya dongeng memiliki andil dan peran tersendiri dalam masyarakat. Hal inilah yang menimbulkan ketertarikan penulis untuk meneliti unsur-unsur humanisme dalam dongeng.

\section{Aspek Humanisme}

Humanisme berasal dari latin, humanis; manusia, dan isme berarti paham atau aliran. Mangun Harjana (1997:101) mengatakan humanisme adalah pandangan yang menekankan martabat manusia dan kemampuannya. Menurut pandangan ini manusia bermartabat luhur, mampu menentukan nasib sendiri dan dengan kekuatan sendiri mampu mengembangkan diri dan memenuhi kepatuhan sendiri mampu mengembangkan diri dan 
memenuhi kepenuhan eksistensinya menjadi paripurna.

Teori Kepribadian Humanistik Menurut

\section{Maslow}

Abraham Maslow (Yusuf Syamsu, 2007: 152) adalah seorang psikolog terkenal. Psikologi humanistik telah menyebar ke berbagai mata pelajaran kemanusiaan seperti geografi dan demografi. Ia dikenal dengan hierarki tentang kebutuhan pada manusia. Konsep Maslow tentang hierarki kebutuhan bahwa kebutuhan yang lebih rendah tingkatnya harus dipuaskan atau minimal terpenuhi secara relatif sebelum kebutuhan yang lebih tinggi tingkatnya menjadi motivator tindakan. Lima kebutuhan yang membentuk hierarki kebutuhan ini merupakan kebutuhan-kebutuhan konatif, artinya bercirikan daya juang atau motivasi. Maslow (1908-1970) berpendapat manusia mempunyai nalurinaluri dasar yang menjadi nyata sebagai kebutuhan. Kebutuhan tersebut adalah:

1. Kebutuhan fisik/biologis;
2. Kebutuhan akan rasa aman;

3. Kebutuhan akan rasa dimiliki (sense of belonging) dan cinta;

4. Kebutuhan akan penghagaan dan harga diri;

5. Kebutuhan aktualisasi/perwujudan diri.

\section{Dongeng}

Tengsoe (1988:166) mengemukakan bahwa dongeng adalah cerita khayal semata yang sulit dipercaya kebenarannya. Dalam dongeng disajikan hal-hal yang ajaib, aneh, dan tidak masuk akal. Dahulu dongeng diciptakan untuk anak kecil, isinya penuh dengan nasihat. Dongeng muncul pertama kali pada zaman sastra purba di Indonesia. Pada mulanya, dongeng tergolong sastra oral atau sastra lisan, yaitu sastra yang disampaikan dari mulut ke mulut.

Danandjaja (2007: 83) mengemukakan "Dongeng adalah cerita pendek kolektif kesusastraan lisan, cerita prosa rakyat yang tidak dianggap benar-benar terjadi. Dongeng diceritakan terutama untuk 
hiburan walaupun banyak juga yang melukiskan kebenaran, berisikan pelajaran (moral), atau bahkan sindiran". Jadi, dongeng merupakan replika kehidupan manusia yang dijadikan pelajaran dalam kehidupan nyata.

\section{METODE PENELITIAN}

Penelitian ini adalah deskriptif kualitatif dengan teknik analisis isi. Adapun langkah kajian berupa pengumpulan data dengan membaca secara keseluruhan dan berulang-ulang dongeng. Setelah itu, mendata aspek humanisme yang ada di dalam dongeng. Kemudian memasukkan aspek humanisme tersebut ke dalam tabel. Selanjutnya, mendata tanda kehadiran aspek humanisme dalam dongeng. Akhirnya memasukkan hasil pengelompokan tersebut ke dalam tabel.

\section{HASIL DAN PEMBAHASAN}

Deskripsi informasi penelitian adalah gambaran mengenai data yang diteliti. Data yang diteliti yaitu 10 dongeng anak yang melegenda di Indonesia, berasal dari dalam negeri dan luar negeri. Dongengdongeng tesebut berjudul Si Kancil Mencuri Mentimun, Timun Emas dan Raksasa Hijau, Ayam Jantan yang Sombong, Burung Gagak yang Cerdik dan Kendi Air, Cerita Bunga dan Kupu-Kupu, Cerita Anak dan Ayah yang Bijaksana, Saudagar Jerami, Jack dan Pohon Kacang, Petani yang Baik Hati, dan Bawang Merah dan Bawang Putih. Dongeng tersebut diteliti berdasarkan aspek humanisme.

Dari sepuluh dongeng yang diteliti, diperoleh hasil sebanyak 68 unsur humanisme. Aspek humanisme berdasarkan terdiri atas kebutuhan fisiologis, kebutuhan akan rasa aman, kebutuhan dicintai dan disayangi, kebutuhan dihargai, dan kebutuhan aktualisasi diri.

Hasil penelitian akan dijelaskan berdasarkan aspek humanisme, baik pada setiap karangan maupun seluruh karangan. Deskripsi hasil penelitian akan dilengkapi 
pula dengan rekapitulasi aspek-aspek humanisme.

\section{Deskripsi Aspek Humanisme Cerita}

\section{Dongeng si Kancil Mencuri Timun}

Pada Cerita Dongeng si Kancil Mencuri

Timun terdapat 12 aspek humanisme.

Kalimat-kalimat yang mengalami kesalahan tersebut dianalisis sebagai berikut:

1) Kalimat 1

a.Si kancil yang

tahunyaitukebunmilikmonyet, memakanbuahtimundenganlahapdanseba nyak yang mampudiamakan.

b.Aspek humanisme dalam kalimat tersebut adalah kebutuhan fisiologis karena terdapat aktivitas makan yang merupakan kebutuhan dasar.

2) Kalimat 2

Mereka pun menjadi merasa sangat mengantuk dan memutuskan untuk tidur sebentar.

Aspek humanisme dalam kalimat tersebut adalah kebutuhan fisiologis karena terdapat aktivitas tidur yang merupakan kebutuhan dasar.

\section{Deskripsi Aspek Humanisme Dongeng}

\section{Timun Emas dan Raksasa Hijau}

Pada dongengTimun Emas dan Raksasa

Hijau terdapat 9 aspek humanisme.

Kalimat-kalimat yang mengalami kesalahan tersebut dianalisis sebagai berikut:

1) Kalimat 1

$$
\begin{aligned}
& \text { Alkisahpadazamandahulukala, } \\
& \text { adaseorangjandamiskin yang } \\
& \text { tinggalsendiri di tepihutan. }
\end{aligned}
$$

Aspek humanisme dalam kalimat tersebut adalah kebutuhan akan rasa aman karena janda tersebut merasa hidup seorang diri.

2) Kalimat 2

Karenaumurnya yang semakintua, jandaitumerasasemakinsulitmelakukan pekerjaannya.

Aspek humanisme dalam kalimat tersebut adalah kebutuhan fisiologis karena janda tersebut merasa semakin 
tua sehingga mengalami masalah yang berhubungan dengan fisik.

3) Kalimat 3

Dari

bercocoktanamdanmencarikayubakar

di hutanuntukdijual

Aspek humanisme dalam kalimat tersebut adalah kebutuhan fisiologis karena dikisahkan janda tersebut mencari nafkah dengan cara menjual kayu bakar. Tujuannya untuk memenuhi kebutuhan fisik.

4) Kalimat 4

Jandaituseringmerenunginasibnyatiap malam

Aspek humanisme dalam kalimat tersebut adalah kebutuhan fisiologis karena dikisahkan janda tersebut merasakan kegelisahan sehingga tiap malam merenungi nasibnya.

Deskripsi Aspek Humanisme Dongeng Saudagar Jerami

Pada dongengSaudagar Jerami terdapat 3 aspek humanisme. Kalimat- kalimat yang mengalami kesalahan tersebut dianalisis sebagai berikut:

1) Kalimat 1

Suatuhari, Taro

pergikekuiluntukberdoa. "Wahai,

DewaRahmat!

Akutelahbekerjadengansungguh-

sungguh,

tapikehidupankutidakberkercukupan".

"Tolonglahaku agar hidupsenang".

Aspek humanisme dalam kalimat

tersebut adalah kebutuhan fisiologis

karena berhubungan dengan emosi dan merupakan kebutuhan dasar.

2) Kalimat 2

"Taro, dengarbaik-baik.

Peliharalahbaik-baikbenda yang

pertama kali kaudapatkanesokhari.

Ituakanmembuatmubahagia."

Aspekhumanismedalamkalimattersebut adalahkebutuhanakan rasa aman.

Tokohdigambarkanakanmenerimasesua tu yang akanmembuatnyabahagia yang mencerminkansimbolkenyamanan.

3) Kalimat 3 
Petaniitumemandangikaintenun yang

indahitu, danmerasaamatsenang.

Sebagaiucapanterimakasihpetaniitume

njamu Taro

makanmalamdanmempersilakannyame

nginap di rumahnya.

Aspekhumanismedalamkalimattersebut

adalahkebutuhanfisiologiskarenatokoh

dijamupetanisehinggakebutuhandasarn

yaterpenuhi.

Deskripsi Aspek Humanisme Dongeng

\section{Jack dan Pohon Kacang}

Pada dongengJack dan Pohon

Kacang terdapat 9 aspek humanisme.

Kalimat-kalimat yang mengalami

kesalahan tersebut dianalisis sebagai

berikut:

1) Kalimat 1

Ibumenyuruh Jack

pergikepasaruntukmenjualsapimere

kasatu-satunyaitu.

Uanghasilpenjualansapitersebutna

ntinyaakandigunakanuntukmembeli

bijigandumdankemudianakanmena namnya di

ladangbelakangrumahmereka.

Aspekhumanismedalamkalimatters

ebutadalahkebutuhanfisiologiskare

natokohmenjualsapiuntukdibelikan

bibitgandumsehinggakebutuhandas

arnyaterpenuhi.

2) Kalimat 2

Keesokanharinya,

Jack

pergikepasaruntukmenjualsapinya.

Aspekhumanismedalamkalimatters

ebutadalahkebutuhanfisiologiskare

natokohmenjualsapisehinggakebutu

handasarnyaterpenuhi.

3) Kalimat 3

"Janganmenghina, $y a !$

Iniadalahkacangajaib.

Jikakaumenanamnyadanmembiark

annyasemalam,

makapagiharinyakacanginiakantu

mbuhsampaikelangit, $\quad$ kata

kakekitumenjelaskan.

Aspekhumanismedalamkalimattersebutada

lahkebutuhanakandihargaikarenatokohberu 
sahamempertahankanpendapatnyaterhadap cemoohan orang-orang.

\section{Deskripsi Aspek Humanisme Dongeng}

\section{Petani yang Baik Hati}

Pada dongengPetani yang Baik Hati terdapat 10 aspek humanisme. Kalimat-kalimat yang mengalami kesalahan tersebut dianalisis sebagai berikut:

1) Kalimat 1

$D i$ suatudesa, hiduplahseorangpetani yang sudahtua.

Petaniinihidupseorangdiridansang atmiskin, pakaiannyapenuhdengantambaland anrumahnyaterbuatdarigubukkayu. Musimdinginsudahtiba, Pak Petanitidakpunyamakanan, jugatidakmempunyaikayubakaruntu kmenghangatkandiri, jadihariini Pak
Petanihendakpergikepasaruntukme ncaripekerjaan.

Aspek humanisme dalam kalimat di atas adalah kebutuhan fisiologis karena tokoh mengalami kelaparan dan kedinginan.

2) Kalimat 2

Pak

PetanimerawatBurungCamarkecilit udenganpenuhkasihsayang.

Diaselalumembagisetiapmakanan yang diperolehnyadaribekerja di pasar.

Aspekhumanismedalamkalimat di atasadalahkebutuhanuntukdicintaid andisayangi,

digambarkantokohmerawatburungc amardenganpenuhkasihsayang.

3) Kalimat 3

TernyataBurungCamaritukembali, di paruhnyaterdapatbenihtanaman. Aspekhumanismedalamkalimat di atasadalahkebutuhanuntukdicintaid andisayangi,

digambarkantokohmendapatbalasan 
ataskasihsayang

yang

diberikanpadaburungcamar.

\section{Deskripsi Aspek Humanisme Dongeng}

\section{Ayam Jantan yang Sombong}

Pada dongengAyam Jantan yang

Sombong terdapat 6 aspek humanisme.

Kalimat-kalimat yang mengalami

kesalahan tersebut dianalisis sebagai

berikut.

1) Kalimat 1

Tapisayangnya, ayamjantan yang

satunyaselalubersikapserakah.

Aspekhumanismepadakalimatterse

butadalahkebutuhanfisiologiskaren

adigambarkansifat-

sifatmanusiamelaluiperumpamaanh

ewan.

2) Kalimat 2

Melihatkawannyalaritungganglang

gang, ayamjantan yang

sombongtersebutmerasasangatpuas

Aspekhumanismepadakalimatterse

butadalahkebutuhanfisiologiskaren adigambarkansifat-

sifatmanusiamelaluiperumpamaanh

ewan.

3) Kalimat 3

Apalagimerekadilihatoleh para

ayambetina yang

daritadimencarimakan di

sekitarmereka. Hal

tersebutmembuatayamjantan yang

sombongitumenjadibesarkepaladan

semakinmembanggakandirinya.

Aspekhumanismepadakalimattersebutadala

hkebutuhanakandihargai,

terlihatdariperilakuayam yang

membanggakandiri.

Deskripsi Aspek Humanisme Dongeng

Burung Gagak yang Cerdik dan Kendi

Air

PadaDongeng Burung Gagak yang

Cerdik dan Kendi Airterdapat 3 aspek humanisme. Kalimat-kalimat yang mengalami kesalahan tersebut dianalisis sebagai berikut.

1) Kalimat 1 
Padasuatuhari,

para

hewanmemutuskanuntukpindahmen

caritempatbaru

yang

memilikisumber air yang

masihmengalir.

Aspekhumanismepadakalimat di atasadalahkebutuhanfisiologiskaren

a para hewantersebutmencari air agar terpenuhikebutuhanfisiknya.

2) Kalimat 2

Ketikaburunggagakituhampirputus

asakarenamerasahampirmatikaren

akehausan, diamelihatkerikil di

sampingkendiitu. Lalutiba-

tibamunculsebuah ide di benaknya.

Diakemudianmengumpulkanbanyak

kerikil yang ada di

sekitartempatitu.

Kemudiandiamemasukansatu per

satukedalamkendi yang berisi air tersebut. Lambatlaun, kendi yang

mulaiterisipenuhdengankerikilmem

aksa air yang ada di

dalamnyauntuknaikkeatasdankelua

rdarikendi.
Aspekhumanismepadakalimatterse

butadalahaktualisasidirikarenaburu nggagaktersebutberhasilmenemuka

n

ide

dandapatmemecahkanmasalahnya.

\section{Deskripsi Aspek Humanisme Dongeng}

\section{Cerita Bunga dan Kupu-Kupu}

Pada dongengCerita Bunga dan Kupu-kuputerdapat $\quad 8 \quad$ aspek humanisme. Kalimat-kalimat yang mengalami kesalahan tersebut dianalisis sebagai berikut:

1) Kalimat 1

Diasangatrakusdalammemakandau n-daun, sehinggabanyakpohon yang takmaudiatinggali.

Aspekhumanismedalamkalimatters ebutadalahkebutuhanfisiologiskare namengisahkan sang ulat yang rakus.

2) Kalimat 2

Izinkanakutinggal $d i$ sinikarenaakutaklagimemilikirumah lain. 
Aspekhumanismepadakalimattersebuta dalahkebutuhanakan rasa amankarena sang ulattidakdiperbolehkantinggal di semuapohonsehinggaiamerasatidakme milikitempattinggal.

3) Kalimat 3

MendengarkisahLiliulat yang sangatsedih, bungamataharimenjadisangatiba Aspekhumanismedalamkalimattersebut adalahkebutuhanfisiologiskarenaterdap atpengungkapanemosionalsepertisedih daniba.

\section{Deskripsi Aspek Humanisme Dongeng}

\section{Cerita Anak dan Ayah yang Bijaksana}

Pada dongengCerita Anak dan Ayah yang Bijaksanaterdapat 4 aspek humanisme. Kalimat-kalimat yang mengalami kesalahan tersebut dianalisis sebagai berikut:

1) Kalimat 1

Perjalanan yang cukupjauhmembuat ayah dananakitucukupkelelahan. Aspekhumanismepadakalimattersebuta dalahkebutuhanfisiologiskarenadigamb arkan ayah dananakmengalamikelelahansecarafisik akibatperjalananjauh.

2) Kalimat 2

Hinggatanpasengaja sang anakterpelesetdanhampirjatuh.

Denganspontananakituberteriakkarena kaget. "Waaaaahhhhh..." tapi sang ayah

dengancekatanmerengguttangananakn yadanmembantunyauntukkembaliberdi ri.

Aspekhumanismepadakarangantersebutada lahkebutuhanakan rasa amankarenadigambarkan sang ayah menyelamatkananakdengancekatansehingg a sang anaktidakmengalamikecelakaan.

Deskripsi Aspek Humanisme Dongeng Cerita Bawang Merah dan Bawang Putih Pada dongengCerita Bawang Merah dan Bawang Putihterdapat 4 aspek humanisme. Kalimat-kalimat yang mengalami kesalahan tersebut dianalisis sebagai berikut:

1) Kalimat 1 


\begin{tabular}{|l|l|l|l|}
\hline No. & $\begin{array}{l}\text { Aspek } \\
\text { Humanisme }\end{array}$ & Jumlah & $\%$ \\
\hline 1. & $\begin{array}{l}\text { Kebutuhan } \\
\text { fisiologi dasar }\end{array}$ & 29 & $42,65 \%$ \\
\hline 2. & $\begin{array}{l}\text { Kebutuhan } \\
\text { akan rasa } \\
\text { aman }\end{array}$ & 14 & $20,59 \%$ \\
\hline & $\begin{array}{l}\text { Kebutuhan } \\
\text { untuk dicintai } \\
\text { dan disayangi }\end{array}$ & 6 & $8,82 \%$ \\
\hline 4. & $\begin{array}{l}\text { Kebutuhan } \\
\text { untuk dihargai }\end{array}$ & 10 & $14,71 \%$ \\
\hline 5. & $\begin{array}{l}\text { Kebutuhan } \\
\text { aktualisasi diri }\end{array}$ & 9 & $13,24 \%$ \\
\hline & Jumlah & $\mathbf{6 8}$ & $\mathbf{1 0 0 \%}$ \\
\hline & Dahulukala, \\
& yadasebuahkeluarga \\
\hline
\end{tabular}

Merekamemilikiseorangputeri yang diberinamabawangputih.

Aspek humanisme pada kalimat tersebut adalah kebutuhan fisiologis karena menceritakan sebuah keluarga yang hidup bahagia.

2) Kalimat 2

Sebenarnyaniatayahnyaadalah agar

bawangputihtakkesepiandanmemili

kiteman yang membantunya di rumah.

Aspek humanisme pada kalimat tersebut adalah kebutuhan akan rasa aman. Sepeninggal ibunya, sang ayah menikah lagi agar putrinya merasa aman dan tidak kesepian

\section{Tabel Persentase Aspek Humanisme pada Dongeng}

\section{SIMPULAN}

Penelitian yang dilakukan terhadap 10 dongeng anak Indonesia menghasilkan sejumlah data dan temuan tentang aspekaspek humanisme. Dari 10 dongeng yang diteliti ditemukan sebanyak 68 aspek humanisme.

Aspek humanisme yang ditemukan dalam dongeng akan diuraikan secara berurutan dari yang pemunculannya paling banyak yaitu kebutuhan fisiologi dasar sebanyak 29 atau 42,65\%; kebutuhan akan rasa aman sebanyak 14 atau 20,59\%; kebutuhan untuk dihargai sebanyak 10 atau 14,71\%; kebutuhan aktualisasi diri sebanyak 9 atau 13,24\%; kebutuhan untuk dicintai atau disayangi sebanyak 6 atau $8,82 \%$. 


\section{DAFTAR PUSTAKA}

Danandjaja, James. 2007. Folklor Indonesia Ilmu Gosip, Dongeng, dan Lain-lain. Jakarta: Temprint.

Harjana, Mangun.1997. Isme-Isme Dari A Sampai Z. Kanisius: Yogyakarta.

Maslow, A. H. 1943. A Theory of Human Motivation.Psychological Review. New York: D. Van Nostrand.

1968. Toward a Psychology of Being (2nd ed.). New York: D. Van Nostrand.

Tjahjono, Liberatus Tengsoe. 1988. Sastra Indonesia Pengantar Teori dan Apresiasi, Ende Flores: Nusa Indah.

Yusuf, Syamsu L.N. 2008. Teori Kepribadian. Bandung: Remaja Rosdakarya.

\section{Internet:}

http://www.Telaga.org/ringkasan.php?Kep ribadian.htm, diakses pada 14 Juli 2016.

http://www.Indonesiaindonesia.com/f/7426 5-pengertian-perasaan, diakses pada 14 Juli 2016.

http://ceritacenter.blogspot.co.id/2015/09/ cerita-anak-dan-ayah-yangbijaksana.html, diakses 16 Juli 2016. 
Bahastra, Oktober 2016, Volume XXXVI, Nomor 1 